\title{
Measurement of the Thermal Conductivity of Argon, Krypton, and Nitrogen in the Range $800-2000^{\circ} \mathrm{K}$
}

\author{
Francis M. Faubert and George S. Springer \\ Fluid Dynamics Laboratory, Department of Mechanical Engineering, The University of Michigan, Ann Arbor 48105
}

(Received 12 April 1971)

\begin{abstract}
The thermal conductivities of argon, krypton, and nitrogen were measured at $760 \mathrm{~mm} \mathrm{Hg}$ in the temperature range $800-2000^{\circ} \mathrm{K}$. Two thermal conductivity columns of different outside diameters were used in the experiments to provide an assessment of the convective heat transfer. In addition, potential leads were employed to minimize convection and end effects. The thermal conductivity values obtained were compared with existing data, with results of viscosity measurements, and with theoretical predictions.
\end{abstract}

\section{INTRODUCTION}

Although the need for accurate thermal conductivity values of high temperature gases is evident, all but a small fraction of the past investigative effort has been directed towards thermal conductivity measurements near room temperatures. With increasing temperature both the number of data available and their accuracy decrease rapidly. In this paper, an apparatus is described that is suitable for accurate determination of thermal conductivities of gases up to $2000^{\circ} \mathrm{K}$, and thermal conductivity data are reported for argon, krypton, and nitrogen in the range $800-2000^{\circ} \mathrm{K}$.

Of the many different methods that have been employed in the past to measure thermal conductivities of gases (e.g., see Refs. 1 and 2), the concentric cylinder type apparatus has been most often used because it is relatively simple and provides reliable data, at least at low temperatures. At temperatures above $\sim 800^{\circ} \mathrm{K}$, the application of this apparatus is beset by difficulties. If small temperature differences are maintained between the cylinders, then temperature fluctuations may occur which are large compared to the applied temperature difference; if large temperature gradients are allowed, then losses through the supports (end losses) and convective heat transfer become significant. Nevertheless, because the concentric cylinder method offers the possibility of good accuracy and precision many attempts have been made to extend its applicability to higher temperatures. Rothman and Bromley ${ }^{3}$ and Vines ${ }^{4}$ used the concentric cylinder type apparatus up to 1000 and $1200^{\circ} \mathrm{K}$, respectively. In order to minimize convective heat transfer these investigators maintained small gap sizes between the cylinders. In this apparatus it is difficult to ensure the concentricity of the cylinders and, furthermore, elaborate guard heaters are needed to prevent excessive end losses from the inner cylinder. These shortcomings may be overcome by replacing the relatively large diameter $(\sim 0.6-3.5 \mathrm{~cm})$ inner cylinder by a fine wire (conductivity column). While this method has been widely used at low temperatures, Blais and Mann ${ }^{5}$ were the first to extend this method to higher temperatures, and to utilize large temperature differences between the wire and the outer cylinder. Blais and Mann performed approximate calculations which suggested that convection effects were negligible in their long $(8 \mathrm{ft}$ ) and narrow (1.22-in. diam) test section. With this assumption they determined thermal conductivities of helium and hydrogen between 1000 $2000^{\circ} \mathrm{K}$. In these experiments heat loss from the entire length of the wire was measured.

Following Blais and Mann, conductivity columns were employed by Vargaftik and Zimina ${ }^{6,7}$ (argon and nitrogen up to $1300^{\circ} \mathrm{K}$ ), Timrot and Umanskii ${ }^{8-10}$ (helium up to $2400^{\circ} \mathrm{K}$, hydrogen and argon up to $2000^{\circ} \mathrm{K}$, and kyrpton up to $1300^{\circ} \mathrm{K}$ ), Saxena and his co-workers ${ }^{11-16}$ (helium up to $1350^{\circ} \mathrm{K}$, neon, nitrogen, krypton, xenon, carbon monoxide, and oxygen up to $1500^{\circ} \mathrm{K}$ ), and Desmond ${ }^{17}$ (argon and helium up to $1300^{\circ} \mathrm{K}$ ). Similarly to Blais and Mann, Timrot and Umanskii and Saxena et al. allowed large temperature gradients in the gas. However, unlike Blais and Mann, Timrot and Umanskii attached a potential lead to the wire, while Saxena et al. used two sections both having the same diameter but different lengths. With these modifications, corrections could be made for those end effects which occurred beyond the potential lead ${ }^{8-10}$ or at distances from the wire ends equal to the difference between the lengths of the two cylinders. ${ }^{11-16}$ Vargaftik and Zimina and Desmond reduced convection and end losses by immersing the entire test section in a constant temperature bath and by maintaining small $\left(\sim 30-40^{\circ} \mathrm{C}\right.$ ) temperature differences between the wire and the outer cylinder.

Although the foregoing methods $s^{6-17}$ minimize convective and end effects they do not ensure that these effects are eliminated. Hence convection and end losses may still affect the results. It would be desirable, therefore, to perform experiments in which the influence of these effects is not only minimized, but can also be assessed. One possible approach toward this goal is to perform the experiments at reduced pressures. $^{5,9-16}$ However, this procedure may introduce difficulties such as excessive temperature jump at the wire. In this investigation a modified form of the column method was employed which differed somewhat from those used previously. Two columns were used which 


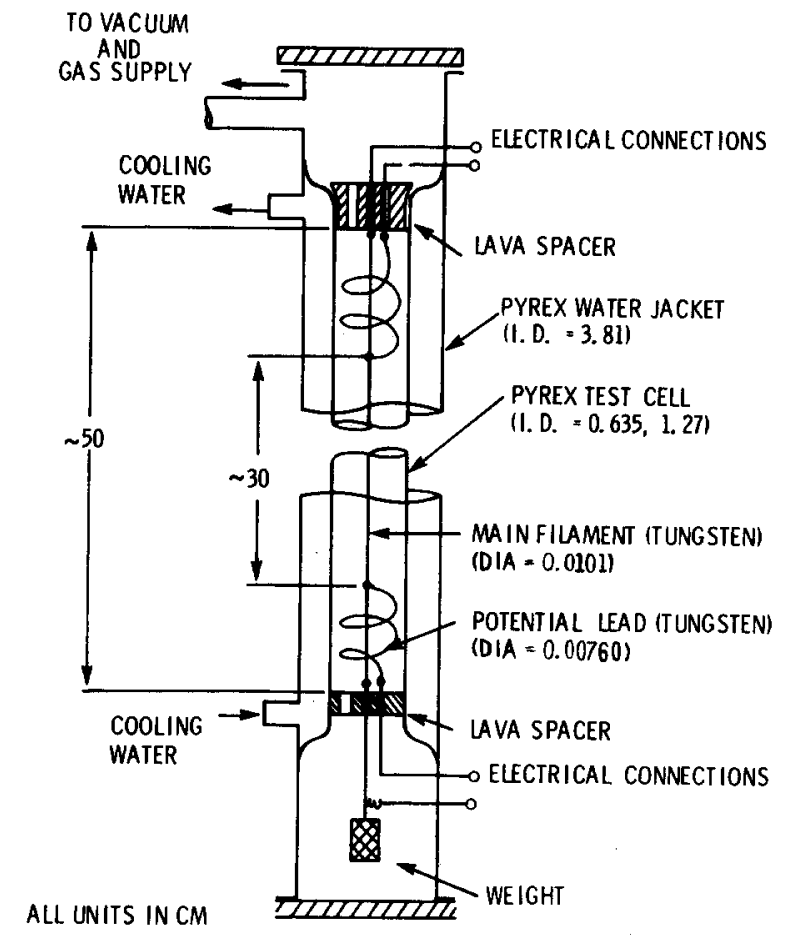

Frg. 1. Schematic of conductivity column.

were identical except for the diameters of the outside cylinders. Since convective effects vary with the cube of the diameters, convective effects present in the experiments would be manifested by differences in the thermal conductivity values obtained with the two different columns. Details of the apparatus are given in the following section.

\section{EXPERIMENTAL APPARATUS AND PROCEDURE}

The experimental apparatus consisted of the conductivity columns, the electrical system, and the vacuum system.

Two columns were used each consisting of a 0.0101 $\mathrm{cm}$-diam and $50-\mathrm{cm}$-long tungsten filament, mounted coaxially in a 56 -cm-long vertical, precision bore Pyrex tube (Fig. 1). The two columns were identical except for the inside diameters of these tubes, which were 0.635 and $1.27 \mathrm{~cm}$, respectively. The filaments were resistance welded to $0.0760-\mathrm{cm}$ diam tungsten "rods," which were attached to precision machined lava spacers placed at each end of the columns. The top spacers were firmly mounted, while the bottom ones were allowed to slide in the tubes to compensate for the expansion of the filaments at higher temperatures. Holes through the spacers allowed the gas to pass through them. Each filament was accurately centered in the tube by viewing the filament-tube assembly through a shadowgraph (50X magnification) and adjusting the support rods as needed. Approxi- mately $10 \mathrm{~cm}$ from each end of the filament a 0.00761 $\mathrm{cm}$-diam wire (potential lead) was spot welded to the filament. The potential leads were wound in a loose coil ( $\sim$ three turns) and were also attached to the lava spacers by 0.0760 -cm-diam tungsten "rods." The use of these potential leads permitted measurements to be made from the center section of the main filaments thereby minimizing the effects of convection and end losses. These effects could also have been reduced by using two columns of different length. ${ }^{11-16}$ The potential lead arrangement was selected here to avoid the use of four columns. The filaments were kept at a constant tension by an $8 \mathrm{~g}$ weight attached to the bottom lava spacers. The top and bottom of the test sections were closed with appropriate flange seals.

Each column was surrounded by a Pyrex jacket, through which water was circulated constantly at a rate of about $10 \mathrm{liter} / \mathrm{min}$. The water temperatures at the inlet and outlet ports were monitored with thermocouples and were kept within $0.1^{\circ} \mathrm{C}$ at about $25^{\circ} \mathrm{C}$.

The electrical leads were fed through the Pyrex envelope and were attached to the top and bottom tungsten rods above and below the respective lava spacers. Power to the filament was provided by a highly regulated dc power supply. The current through the filament was determined by measuring the potential drop across a high precision standard resistor $(0.0999996 \Omega)$ placed in series with the filament, and kept in a constant temperature oil bath. The potential drop across the filament between the potential leads was also measured, and thus the power dissipated could be readily calculated. The electrical measurements were made with EDC Models MV $100 \mathrm{~N}$ and VS-1000/007 high precision dc voltage standards.

The columns were connected to the vacuum pumps and gas supply bottles through a Pyrex vacuum system. The lowest attainable pressure in the system was $\sim 5 \times 10^{-7} \mathrm{~mm} \mathrm{Hg}$ as indicated by an ionization gauge. With the test gas in the system the pressure was measured by a $U$ tube mercury manometer, and was maintained constant at $760 \mathrm{~mm} \mathrm{Hg}$. The test gases were "research grade" supplied by the Matheson Company. Each gas was admitted into the column through a dry ice-acetone cold trap and, prior to taking data, the system was purged several times with the gas.

The same experimental procedure was used with both the large and small diameter columns. First, the system was evacuated and the filament was kept at $2400^{\circ} \mathrm{K}$ for $24 \mathrm{~h}$ to stabilize its physical and electrical properties. Then, the resistance vs temperature characteristic of the filament was determined in the range $1100-2000^{\circ} \mathrm{K}$. The filament temperature was measured with a calibrated Pyro Micro Optical pyrometer. The recorded temperature was corrected for the apparent emissivity of the tungsten filament ${ }^{18} \quad(\epsilon=0.43$ at $\lambda=$ 
$0.65 \mu$ ) and for absorption through the glass surfaces of the outer cylinder and water jacket. ${ }^{1,20}$ The correction due to the water around the column was evaluated experimentally and was found to be insignificant. The pyrometer was not sufficiently accurate below $1100^{\circ} \mathrm{K}$. It was found, however, that above $1100^{\circ} \mathrm{K}$ the slope of the resistance vs temperature curve agreed closely with the values given by Smithells. ${ }^{21}$ Therefore, the curve was extrapolated to $800^{\circ} \mathrm{K}$ using the appropriate slopes from Smithells. The resistance-temperature characteristic of the filament was checked throughout the experiments.

Once the calibration was completed the filament temperature was set at the required value and the heat loss from the center section of the filament (i.e., the section between the potential leads) was measured both in vacuum $\left(\bar{Q}_{f}{ }^{\nu}\right)$ and in the presence of the gas $\left(\bar{Q}_{f}\right)$. In addition, the temperature distribution along the filament was measured. This latter information was needed to correct for the nonuniformity of the filament temperature near the potential leads (see next section). The length of the filament between the potential leads, $L$, was also measured throughout the experiment with a cathetometer. For further experimental details the reader is referred to Ref. 22.

\section{TREATMENT OF THE DATA}

Due to the large temperature differences between the filament and the outer cylinder, the gas moves upward near the filament and downward in the outer portion of the column. In addition to this "primary" motion, multicellular secondary motion may also occur in the column. Both of these motions may result in significant heat convection from the filament. However, if only the primary motion is present then at some distance from each end of the column the axial temperature gradients diminish and the heat convected from the filament, $\bar{Q}_{c}$, becomes negligible compared to the conductive and radiative heat transfer. ${ }^{5,23-28}$ The distance from the ends of the column where this condi-

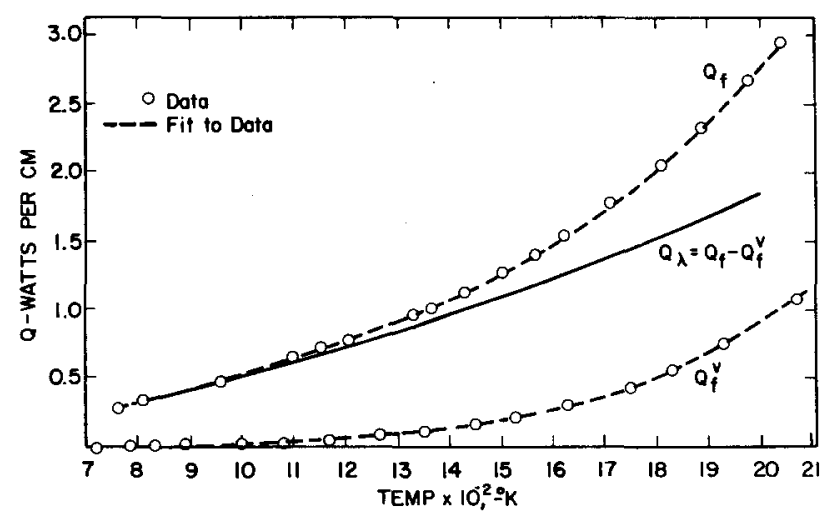

FIG. 2. Heat transfer from the filament in vacuum and in the presence of nitrogen (small column).

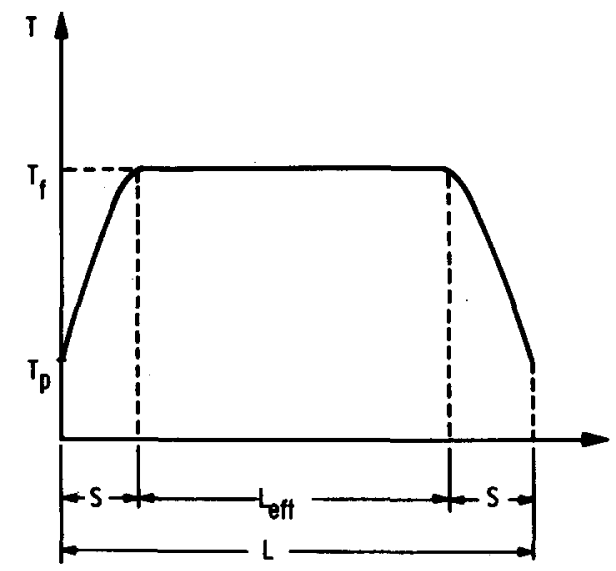

Fig. 3. Schematic of temperature variation along the filament between the potential leads.

tion is met can be approximated by ${ }^{25,29}$

$$
Z_{p}=D(\mathrm{Ra} / 7670)(\mathrm{Ra} \geq 7670),
$$

where $D$ is the inner diameter of the outer cylinder and $\mathrm{Ra}$ is the Rayleigh number defined as

$$
\mathrm{Ra} \equiv\left[\left(g \rho^{2} \Delta T D^{3} / \eta^{2} T\right)\left(C_{p} \eta / \lambda\right)\right]_{T=\bar{T}} .
$$

In Eq. (2) $g$ is the gravitational acceleration, $\rho$ the density, $\eta$ the viscosity, $C_{p}$ the constant pressure specific heat, and $\lambda$ the thermal conductivity of the gas. $\Delta T$ is the temperature difference between the filament and the outer cylinder, and $\bar{T}$ is the average temperature of the gas. In the present experiments the maximum Rayleigh number was $6 \times 10^{4}$ for the large column (argon and nitrogen) and $2.6 \times 10^{4}$ for the small one (argon, nitrogen, and krypton). For these Rayleigh numbers Eq. (2) gives $Z_{p}$ values of 9.7 and $2.11 \mathrm{~cm}$, respectively. In our apparatus the potential leads were attached at $10 \mathrm{~cm}$ from the ends. Since this is more than the calculated value of $9.7 \mathrm{~cm}$, therefore, at the center section of the filament $\bar{Q}_{c}$ should be negligible. For krypton in the large column the Rayleigh numbers were somewhat higher. As will be shown in the next section, even in this case convection did not appear to affect the results.

Multicellular secondary motion arises in the column when a certain value of the Rayleigh number is exceeded. ${ }^{26-28}$ An expression for the critical Rayleigh number was recommended by Thomas and de VahlDavis. ${ }^{26}$ For our experimental conditions this expression gives critical Rayleigh numbers of $5 \times 10^{11}$ and $1 \times 10^{12}$ for the large and small columns, respectively. The Rayleigh numbers of the present experiments (see above) were considerably below these values and, consequently, multicellular secondary motion was not expected to occur in the test section.

The foregoing results imply that convective effects could be neglected in the present experiments. To assess the validity of this conclusion, two different diameter columns were used in the measurements. The presence 


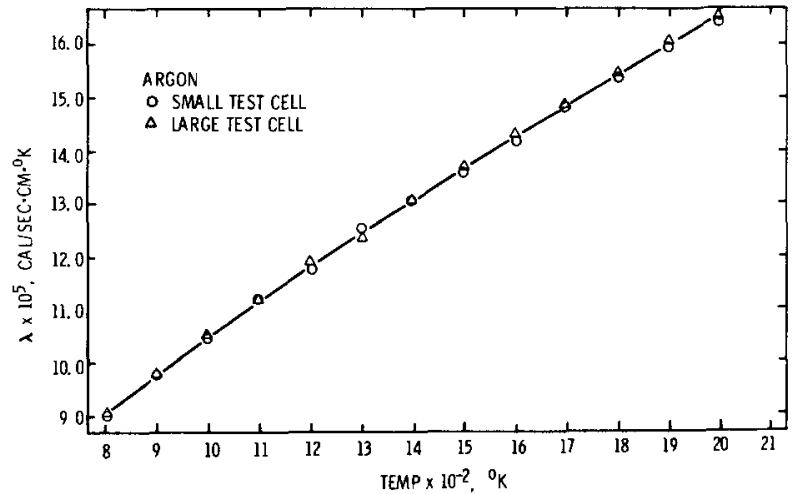

Fic. 4. Experimental results for argon $(O$, small column; $\triangle$, large column). Solid line, Eq. (11).

of any convection effect would be manifested by a difference in the thermal conductivity values thus obtained because convection depends upon the Rayleigh number, that is, upon the cube of the column diameter.

Neglecting the convective heat transfer, in the presence of the gas an energy balance for the filament section between the potential leads gives

$$
\bar{Q}_{f}=\bar{Q}_{\lambda}+\bar{Q}_{r}+\bar{Q}_{p}
$$

where $\bar{Q}_{f}$ is the power input to the filament, $\bar{Q}_{\lambda}$ is the heat conducted from the filament to the gas, $\bar{Q}_{r}$ is the heat loss from the filament due to radiation, and $\bar{Q}_{p}$ is the heat loss through the potential leads. On a unit length basis $(Q \equiv \bar{Q} / L)$, Eq. (3) is

$$
Q_{\lambda}=Q_{f}-\left(Q_{r}+Q_{p}\right) \text {. }
$$

In vacuum $\left(Q_{\lambda} \cong 0\right)$ the energy balance for the filament is

$$
Q_{i}{ }^{v}=Q_{r}{ }^{0}+Q_{p}{ }^{p},
$$

where the superscript indicates measurements in vacuum. As a first approximation it can be assumed that the radiation and potential lead losses in vacuum and in gas are the same, i.e., $Q_{r}+Q_{p}=Q_{r}{ }^{v}+Q_{p}{ }^{v}$. Then, Eqs. (4) and (5) yield

$$
Q_{\lambda}=Q_{f}-Q_{f}{ }^{0} .
$$

TABLE I. Estimate of random errors (percent).

\begin{tabular}{lllll}
\hline \hline \multirow{4}{*}{ Argon } & & \multicolumn{3}{c}{ Temp. range } \\
\cline { 3 - 5 } & Temp. & $800-1200$ & $1200-1600$ & $1600-2000$ \\
\hline \multirow{4}{*}{ Krypton } & Large column & 2.43 & 2.05 & 1.63 \\
& Small column & 2.03 & 1.77 & 1.53 \\
& Large column & 2.76 & 2.5 & 2.14 \\
& Small column & 2.59 & 2.28 & 1.94 \\
& Large column & 3.08 & 2.54 & 1.98 \\
& Small column & 3.00 & 2.33 & 1.85 \\
\hline \hline
\end{tabular}

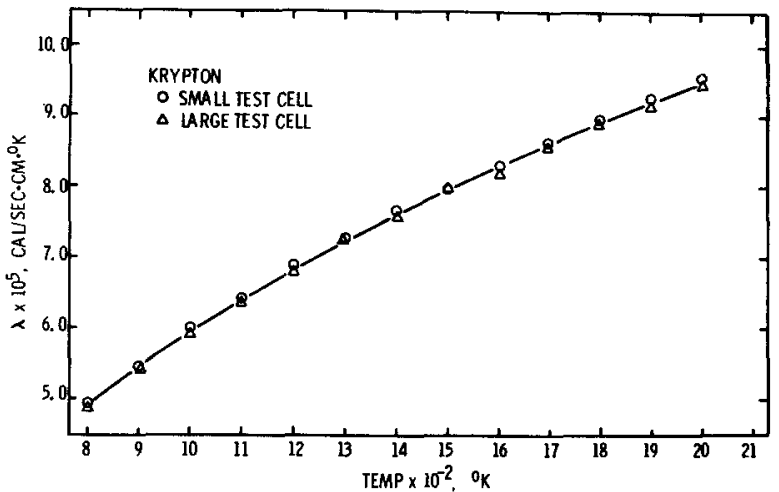

FIG. 5. Experimental results for krypton (O, small column; $\triangle$, large column). Solid line, Eq. (11).

In order to obtain $Q_{\lambda}$ as a continuous function of temperature, the experimentally determined values of $Q_{f}$ and $Q_{f}{ }^{v}$ were plotted vs filament temperature, and a smoothed least squares fit curve was drawn through the data points. $Q_{\lambda}$ was then evaluated by taking differences of the smoothed values at equal temperature intervals. Such a plot is illustrated in Fig. 2 .

Owing to heat losses through the potential leads the filament is not at a uniform temperature and $Q_{r}+Q_{p} \neq$ $Q_{r}{ }^{\nu}+Q_{p}{ }^{v}$. Therefore, a correction must be applied to the $Q_{\lambda}$ value given by $\mathrm{Eq}$. (6). By assuming $Q_{r}=Q_{r}{ }^{2}$, the corrected value of $Q_{\lambda}$ can be expressed as

$$
\begin{aligned}
Q_{\lambda}^{c}=\left(Q_{f}\right)^{c}-\left(Q_{f^{v}}\right)^{c}= & Q_{f}\left(L / L_{\mathrm{eff}}\right)\left(\bar{R}_{\mathrm{eff}} / \bar{R}\right) \\
& -Q_{f}^{v}\left(L^{v} / L_{\mathrm{eff}}^{v}\right)\left(\bar{R}_{\mathrm{eff}}^{\mathrm{v}} / \bar{R}^{v}\right),
\end{aligned}
$$

where $L_{\text {eff }}$ and $\bar{R}_{\text {eff } f}$ are the length and resistance of that portion of the filament which is at the uniform temperature $T_{f}$ (see Fig. 3) and $\bar{R}$ is the total resistence of the filament between the potential leads. With the exception of $\bar{R}_{\text {eff }}$ and $\bar{R}_{\text {eff }}{ }^{\mathrm{v}}$, all parameters on the right-hand side of Eq. (7) were determined experimentally. At most $5 \%$ of the filament was nonuniform in temperature. Therefore, a simple linear variation in temperature between $T_{f}$ and $T_{p}\left(T_{p}\right.$

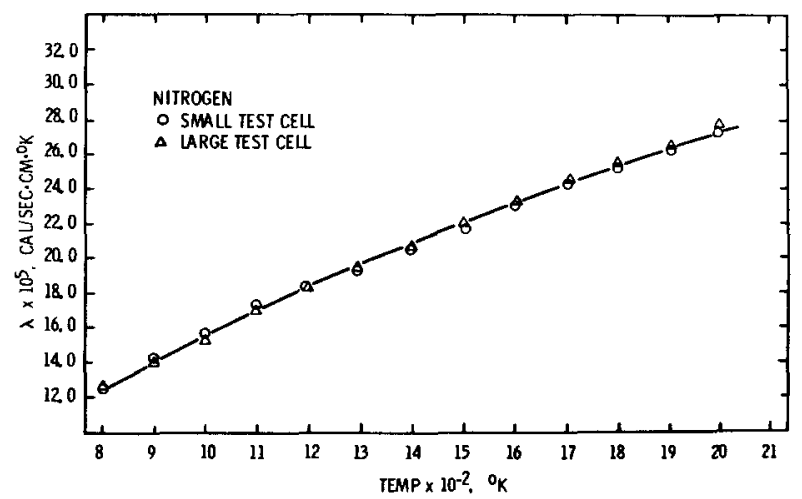

FIG. 6. Experimental results for nitrogen $(O$, small column; $\triangle$, large column). Solid line, Eq. (11). 
being the temperature at the potential lead junction) was assumed to calculate $\bar{R}_{\text {eff }}$ and $\bar{R}_{\text {eff }}{ }^{v}$,

$$
\begin{gathered}
\bar{R}_{\text {eff }}=\bar{R}-2 S\left[R_{p}+\frac{1}{2} \alpha\left(T_{f}-T_{p}\right)\right], \\
\bar{R}_{\text {eff }}=\bar{R}^{v}-2 S^{v}\left[R_{p}^{v}+\frac{1}{2} \alpha^{v}\left(T_{f}^{v}-T_{p}^{v}\right)\right],
\end{gathered}
$$

where $S$ is $\left(L-L_{\mathrm{eff}}\right) / 2, R_{p}$ is the resistance per unit length of the filament at $T_{p}$, and $\alpha$ is the slope of the resistance per unit length vs temperature curve. In analyzing the data it was found that the foregoing corrections were very small, inasmuch as $Q_{\lambda}$ and $Q_{\lambda}{ }^{c}$ and $d Q_{\lambda} / d T$ and $d Q_{\lambda}{ }^{c} / d T$ differed by less than $1.0 \%$ and $0.3 \%$, respectively.

The thermal conductivity of the gas at the filament temperature $T_{f}$ was finally calculated from the expression, ${ }^{22}$

$$
\lambda\left(T_{f}\right)=\left(\frac{d Q_{\lambda}{ }^{c}}{d T}\right)_{T_{f}} \frac{\ln (D / d)}{2 \pi}\left(1+\lambda^{\prime}\right),
$$

where $\lambda^{\prime}$ is a correction due to the temperature drop across the Pyrex outer cylinder,

$$
\lambda^{\prime} \cong \frac{\lambda_{b}}{\lambda_{o}} \frac{\ln [1+(2 w / D)]}{\ln (D / d)}
$$

$\lambda_{b}$ is the thermal conductivity of the gas at the water bath temperature $T_{b}, \lambda_{g}$ is the thermal conductivity of the Pyrex, $d$ is the filament diameter, and $w$ is the wall thickness of the Pyrex envelope $(w=0.158 \mathrm{~cm})$. In the present experiments $\lambda^{\prime}$ was found to be less than 0.0015. $\left(d Q_{\lambda}^{c} / d T\right)_{T f}$ was determined by numerical differentiation based on Stirling's interpolation formula. ${ }^{30}$ Five points at $10^{\circ} \mathrm{C}$ temperature intervals were used for each derivative.

Equation (9) is applicable only if temperature jump effects are negligible, which is the case when the Knudsen number ( $\mathrm{Kn}$ denotes mean free path/filament diam) is less than $\sim 0.002 .^{31,32}$ In our experiments the Knudsen numbers were below this value, and therefore, it was unnecessary to correct for the temperature jump.

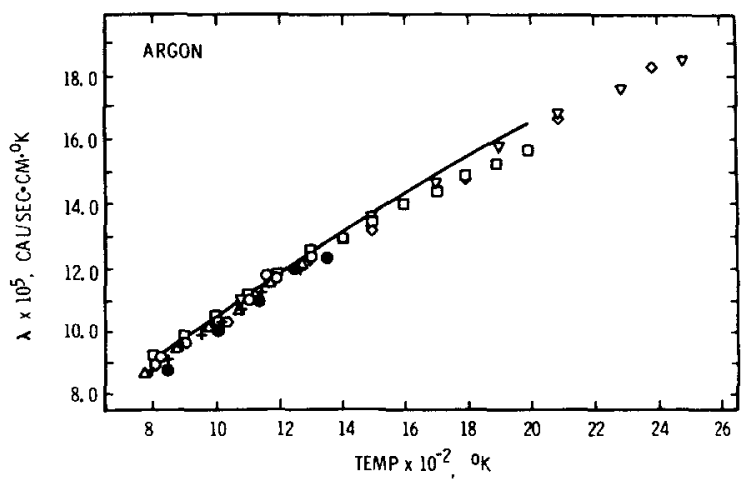

FIG. 7. Thermal conductivity of argon. - Present result [Eq. (11)]; $\diamond$, Collins and Menard ${ }^{36} ;+$, Desmond ${ }^{17} ;$ and Bonilla ${ }^{37} ; O$, Saxena and Saxena ${ }^{12} ; \nabla$, Smiley ${ }^{36} ; \square$, Timrot and Umanskii $; \triangle$, Vargaftik and Zimina ${ }^{6} ; \square$, Vines ${ }^{4}$.

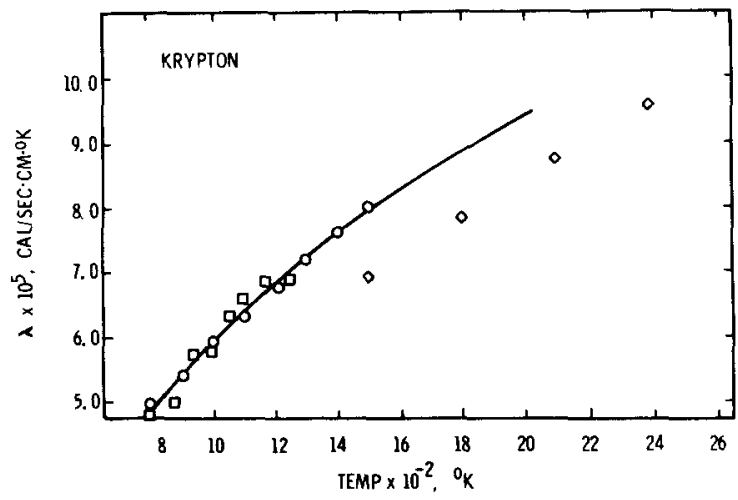

Fig. 8. Thermal conductivity of krypton. -, Present result [Eq. (11) ]; $\diamond$, Collins and Menard ${ }^{36} ; O$, Saxena and Saxena ${ }^{15}$; $\square$, Timrot and Umanskii. ${ }^{10}$

\section{RESULTS AND DISCUSSION}

Thermal conductivities of argon, krypton, and nitrogen were determined at $760 \mathrm{~mm} \mathrm{Hg}$ in the range $800-2000^{\circ} \mathrm{K}$. The experimental results are shown in Figs. 4-6. As can be seen, the data obtained with the large and small columns agree very closely, implying that the assumption of negligible convection effects was reasonable. A detailed error analysis of the data has been made ${ }^{22}$ and a summary of it is given in Table I. The most probable random errors range from $1.5 \%$ to $3.0 \%$. A large part (about $\frac{2}{3}$ ) of these errors was estimated to be due to the numerical differentiation. The good agreement between the results of the two columns suggests that the actual random errors were less than the estimated values. The magnitude of the systematic errors is difficult to assess. However, in view of the good agreements just mentioned it was felt that any systematic errors which might be present might cause at most an additional uncertainty of $1.0 \%$. A least squares fit of the data points results in the equations:

$$
\begin{aligned}
& \text { argon } \\
& \lambda_{\mathrm{Ar}}=0.266 \times 10^{-4}+0.875 \times 10^{-7} T-0.919 \times 10^{-11} T^{2}, \\
& \text { krypton } \\
& \lambda_{\mathrm{Kr}}=0.155 \times 10^{-4}+0.491 \times 10^{-7} T-0.455 \times 10^{-11} T^{2} \\
& \text { nitrogen } \\
& \lambda_{\mathrm{N}_{2}}=0.802 \times 10^{-5}+0.155 \times 10^{-6} \mathrm{~T}-0.100 \times 10^{-10} T^{2} \text {. }
\end{aligned}
$$

Here $T$ is in degrees Kelvin and $\lambda$ is in calories/second. centimeter-degrees Kelvin. The preceding equations synthesize the $\lambda$ values within an average absolute deviation of $0.4 \%$. Polynomials of the type given above are used frequently to correlate thermal conductivity data. According to the Chapman-Enskog method of solution of the Boltzmann equation, ${ }^{33} \lambda \sim T^{1 / 2} /\left(\Omega^{(2,2) *} \sigma^{2}\right)$. 


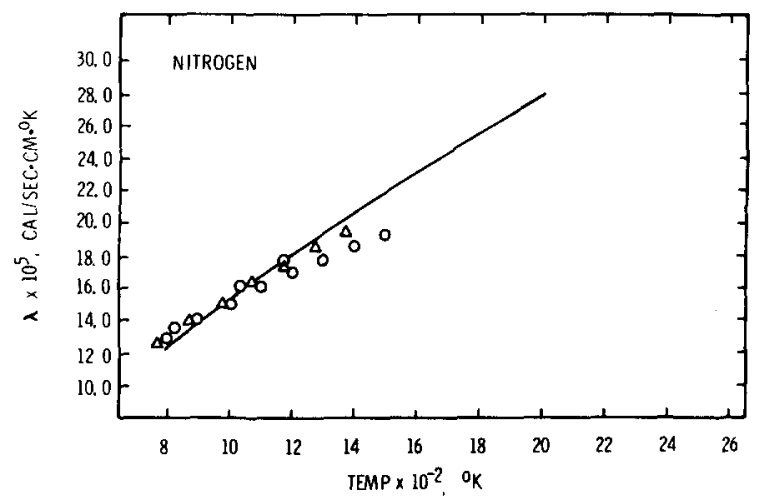

FIG. 9. Thermal conductivity of nitrogen. - Present result [Eq. (11)]; O, Saxena, Gupta, and Saxena ${ }^{14} ; \triangle$, Vargaftik and Zimina ${ }^{7} ; 0$, Vines. ${ }^{4}$

Therefore, for argon and krypton it is physically more meaningful to correlate the group $T^{1 / 2} / \lambda$ against temperature, because this amounts to an empirical determination of the collision integral $\Omega^{(2,2) *}$. We expressed $\ln \lambda / T^{1 / 2}$ in terms of $\ln T$ using both second and first order polynomials, ${ }^{34}$ and found the latter to provide a better fit to the data. For first order polynomials, the calculations yield

$$
\lambda=a T^{0.5+b} \mathrm{cal} / \mathrm{sec} \cdot \mathrm{cm} \cdot{ }^{\circ} \mathrm{K},
$$

where $T$ is in degrees Kelvin. For argon $a=1.172 \times$ $10^{-6}, b=0.1507$, for krypton $a=5.950 \times 10^{-7}, b=$ 0.1684 .

The thermal conductivity values given by Eqs. (11) are compared to previous results ${ }^{4,6,9,12,17,35-37}$ in Figs. 7-9. For argon, below $1500^{\circ} \mathrm{K}$ all existing data agree within $\sim 3 \%$, and the present results fall within this spread.

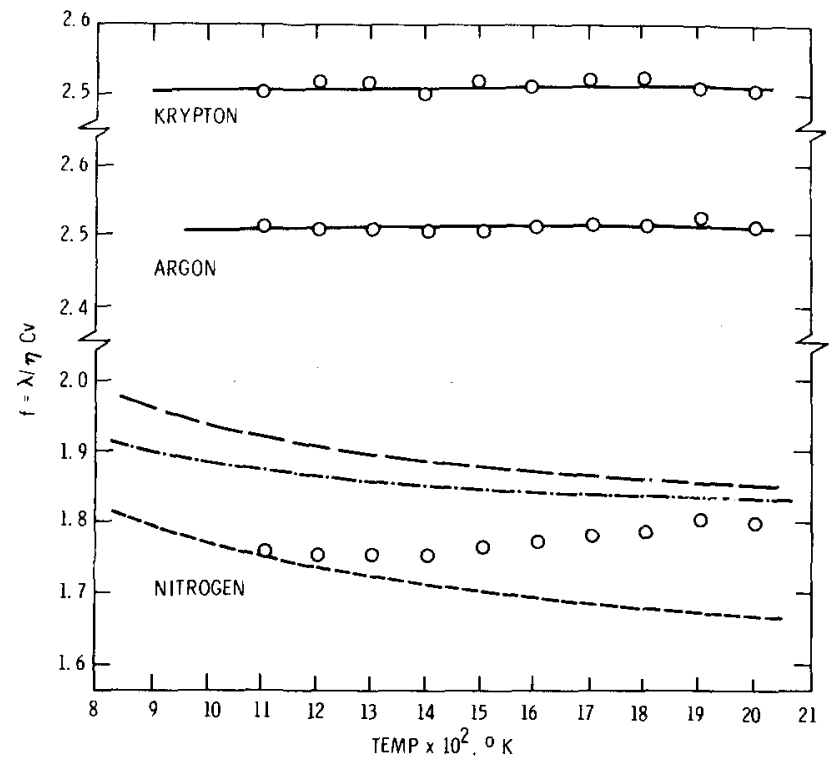

FIG. 10. Comparison between experimental and theoretical volumes of $f .0$, data; -, Lennard-Jones $6-12$; - . - Mason and Monchick ${ }^{42}$; - - - Eucken approximation; - - - , modified Eucken approximation.

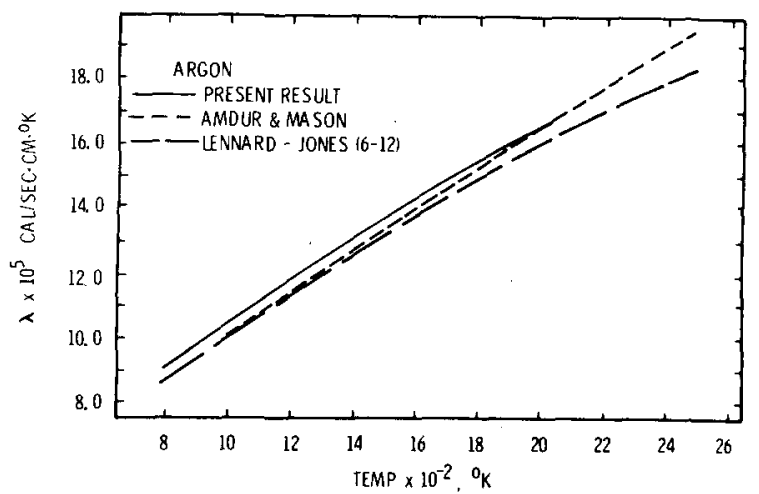

FIG. 11. Comparison between measured and calculated thermal conductivities of argon (for Lennard-Jones $6-12: \epsilon / k=124^{\circ} \mathrm{K}$, $\sigma=3.413 \AA$ ).

Above $1500^{\circ} \mathrm{K}$, the existing data differ by as much as $6 \%$. The present data agree well with the thermal conductivity values obtained with shock tubes by Smiley ${ }^{35}$ and Collins and Menard, ${ }^{36}$ while the data of Timrot and Umanskii ${ }^{9}$ appear to be low above $\sim 1400^{\circ} \mathrm{K}$

Fewer data are available for krypton. The present results agree closely with the measurements of Timrot and Umanskii, ${ }^{10}$ and Saxena and Saxena ${ }^{15}$ up to the limits of their experiments, which were 1200 and $1500^{\circ} \mathrm{K}$, respectively. The measurements of Collins and Menard ${ }^{36}$ fall considerably $(\sim 15 \%)$ below the present results.

For nitrogen the data of this investigation agree well with the data of Vines ${ }^{4}$ and Vargaftik and Zimina. ${ }^{7}$ The agreement with the results of Saxena $e t a l .^{14}$ is fair only below $\sim 1000^{\circ} \mathrm{K}$. At higher temperatures these latter results fall below those of the present investigation and also of Vines and Vargaftik and Zimina.

The accuracy of the thermal conductivity data can be assessed further by the use of the parameter,

$$
f=\lambda / \eta C_{v},
$$

where $\eta$ is the absolute viscosity of the gas (grams/

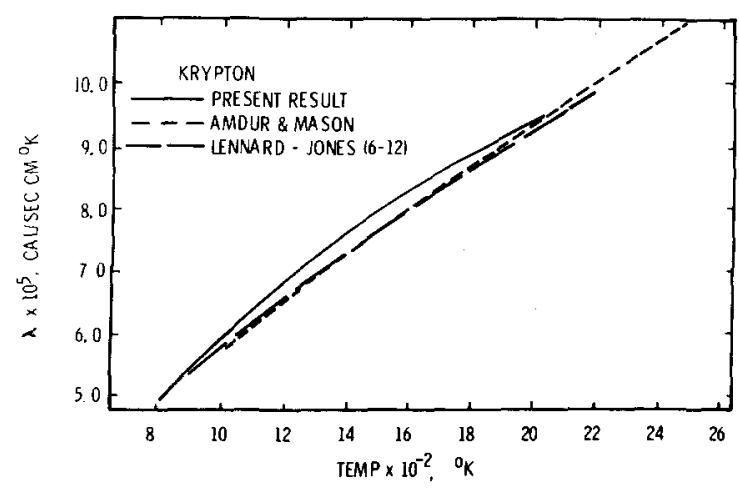

FIG. 12. Comparison between measured and calculated thermal conductivities of krypton (for Lennard-Jones 6-12: $\epsilon / k=190^{\circ} \mathrm{K}$, $\sigma=3.61 \AA$ ). 
centimeter-second) and $C_{0}$ is the constant volume specific heat (calories/gram • degrees Kelvin). The experimental $f$ values were calculated using $\lambda$ given by Eqs. (11), the viscosity data of Refs. 38-40, and the $C_{v}$ values for argon from Ref. 41 . As can be seen from Fig. 10, for argon and krypton the experimental and theoretical values of $f$ agree very closely lending further confidence to the present data. For diatomic gases the theoretical value of the parameter $f$ is not as well established. For nitrogen the Eucken formula, the modified Eucken formula, and the theoretical prediction of Mason and Monchick ${ }^{42}$ yield different results (Fig. 10). The experimental values, also shown in Fig. 10, tend to support Mason and Monchick's calculations, although the results of these calculations appear to be somewhat high. A similar trend was found at lower $\left(600-1100^{\circ} \mathrm{K}\right)$ temperatures. ${ }^{42}$

Finally, the thermal conductivities obtained in this investigation were compared to thermal conductivities calculated using Amdur and Mason's results ${ }^{43}$ and the Lennard-Jones 6-12 potential function ${ }^{33}$ (Figs. 11-13). In both of these calculations the modified Eucken approximation, as given by Hirschfelder, ${ }^{44}$ was used to correct for the internal degres of freedom of nitrogen. The thermal conductivities of nitrogen thus computed are higher than the experimental values, as one might anticipate from Fig. 10. The Lennard-Jones 6-12 results shown in Figs. 11-13 were computed using force constants $(\epsilon / k$ and $\sigma$ ) given by low temperature $\left(\sim 300^{\circ} \mathrm{K}\right)$ viscosity data. ${ }^{33}$ As expected, with these constants the Lennard-Jones 6-12 calculations do not predict correctly the thermal conductivity at high temperatures. The data could also be compared to results obtained from other molecular models. Here we include a comparison between the measured thermal conductivities of argon and values calculated for the potential of Dymond and Alder. ${ }^{45}$ This empirical potential has been deduced by considering different kinds of experimental equilibrium and transport data. For clarity this comparison is not included in Fig. 11, but is

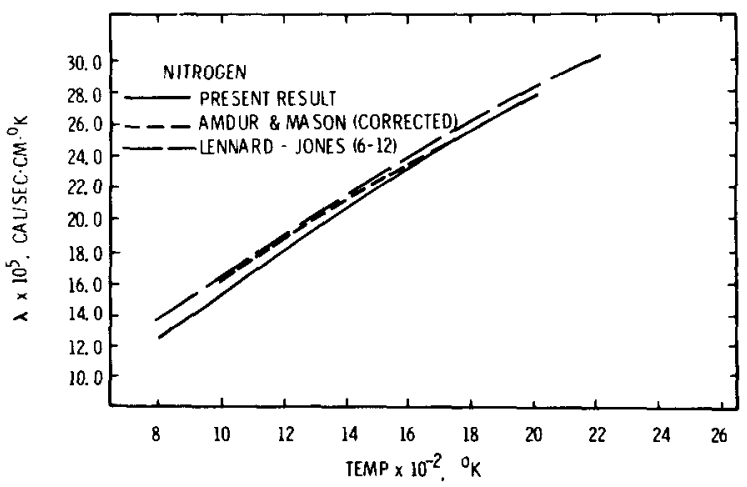

FIG. 13. Comparison between measured and calculated thermal conductivities of nitrogen (for Lennard-Jones 6-12: $\epsilon / k=91.5^{\circ} \mathrm{K}, \sigma=3.681 \AA$ ).
TABLE II. Thermal conductivity of argon. Comparison between the present data [Eq. (11)] and the potential of Dymond and Alder. ${ }^{\mathrm{s}}$

\begin{tabular}{ccc}
\hline & $\begin{array}{c}\text { Thermal conductivity } \lambda \times 10^{6} \\
\mathrm{cal} / \mathrm{sec} \cdot \mathrm{cm} \cdot{ }^{\circ} \mathrm{K}\end{array}$ \\
\cline { 2 - 3 } Temp. $\left({ }^{\circ} \mathrm{K}\right)$ & Present & Dymond and Alder \\
\hline 800 & 90.7 & 88.4 \\
1200 & 118.4 & 116.6 \\
1600 & 143.1 & 141.3 \\
2000 & 164.8 & 163.8 \\
\hline
\end{tabular}

a Reference 45 .

given in Table II. As can be seen, the agreement is quite good between the measured and calculated values.

\section{ACKNOWLEDGMENTS}

The authors wish to thank Mr. H. Ehya for his help in the experiments. The authors also wish to thank Professor J. Kestin, Professor S. C. Saxena, and Professor R. E. Sonntag for their careful reading of the manuscript and for their many valuable comments. This work was supported by the National Science Foundation under Grant No. KG-14006.

${ }^{1}$ N. V. Tsederberg, The Thermal Conductivity of Gases and Liquids (Technology, Cambridge, Mass., 1965).

${ }^{2}$ S. C. Saxena and J. M. Gandhi, J. Sci. Ind. Res. 26, 458 (1967).

${ }^{3}$ A. J. Rothman and L. A. Bromley, Ind. Eng. Chem. 47, 899 (1955).

${ }^{4}$ R. G. Vines, J. Heat Transfer 82, 48 (1960).

${ }^{5}$ N. C. Blais and J. B. Mann, J. Chem. Phys. 32, 1459 (1960).

${ }^{6} \mathrm{~N}$. B. Vargaftik and N. K. Zimina, Teplofiz. Vysokikh Temp. 2, 716 (1964) [High Temp. 2, 645 (1964)].

7 N. B. Vargaftik and N. K. Zimina, Teplofiz. Vysokikh Temp. 2, 838 (1964) [High Temp. 2, 782 (1964)].

${ }^{8}$ D. L. Timrot and A. S. Umanskii, Teplofiz. Vysokikh Temp. 3, 381 (1965) [High Temp. 3, 345 (1965)].

${ }^{2}$ D. L. Timrot and A. S. Umanskii, Teplofiz. Vysokikh Temp. 4, 289 (1966) [High Temp. 4, 285 (1966)]

${ }^{10}$ A. S. Umanskii and D. L. Timrot, in Thermal Conductivity, edited by C. Y. Ho and R. E. Taylor (Plenum, New York, 1969), p. 151.

${ }^{11}$ V. K. Saxena and S. C. Saxena, J. Phys. D. 1, 1341 (1968).

12 V. K. Saxena and S. C. Saxena, Chem. Phys. Letters 2, 44 (1968).

${ }^{13}$ V. K. Saxena and S. C. Saxena, J. Chem. Phys. 48, 5662 (1968).

${ }_{14}$ S. C. Saxena, G. P. Gupta, and V. K. Saxena, Ref. 10, p. 125.

15 V. K. Saxena and S. C. Saxena, J. Chem. Phys. 51, 3361 (1969).

${ }^{16}$ S. C. Saxena and G. P. Gupta, Progr. Aeron. Astron. 23, 34 (1970)

${ }^{17}$ R. Desmond, Ph.D. thesis, University of Minnesota, Minneapolis, Minn. 1968.

${ }^{18}$ D. E. Poland, J. W. Green, and J. L. Margrave, Natl. Bur. Std. (U.S.) Monograph 30 (1961).

${ }^{19}$ P. D. Foote, C. O. Fairchild, and T. R. Harrison, Natl. Bur. Std. (U.S.) Tech. Paper 170 (1921).

${ }^{20}$ H. J. Kostowski and R. D. Lee, Natl. Bur. Std. (U.S.) Monograph 41 (1962).

${ }^{21}$ C. J. Smithells, Tungsten (Chapman and Hall, London, 1952), 3rd ed., p. 177 . 
${ }^{22}$ F. M. Faubert, Ph.D. thesis, The University of Michigan, Ann Arbor, Mich. 1971.

${ }^{23}$ G. K. Batchelor, J. Appl. Math. 12, 209 (1954).

${ }^{24}$ E. R. G. Eckert and W. O. Carlson, Intern. J. Heat Mass Transfer 2, 106 (1961).

${ }^{25}$ W. H. Lipkea and G. S. Springer, Intern. J. Heat Mass Transfer 11, 1341 (1968).

${ }^{26}$ R. W. Thomas and G, deVahl Davis, Proc. Intern. Conf. Heat Transfer Paris-Versailles, 1970 4, NC 2.4 (1970).

${ }_{27}$ J. W. Elder, J. Fluid Mech. 24, 823 (1966).

${ }^{28} \mathrm{C}$. M. Vest, J. Fluid Mech. 36, 1 (1969).

${ }^{29}$ Lipkea and Springer ${ }^{25}$ evaluated the Rayleigh number based on the average temperature $\left[\left(T_{f}+T_{D}\right) / 2\right]$ between filament and outer cylinder, giving the denominator as 4400 . Using the mean temperature $\bar{T}$ (where $\bar{\rho} \bar{T}=$ const) the denominator becomes 7670 .

${ }_{30}$ J. B. Scarborough, Numerical Mathematical Analysis (Johns Hopkins, Baltimore, Md., 1955).

${ }^{3}$ G. S. Springer, in Advances of Heat Transfer, edited by T. F. Irvine, Jr., and J. P. Hartnett (Academic, New York, 1971), Vol. 7 , p. 163 .

${ }^{32}$ D. B. Sheldon and G. S. Springer, Phys. Fluids 11, 1312 (1968).
${ }^{33}$ J. O. Hirschfelder, C. F. Curtis, and R. B. Byrd, Molecular Theory of Gases and Liquids (Wiley, New York, 1967).

${ }^{34}$ The authors are grateful to Professor J. Kestin for suggesting this method of correlation.

${ }^{35}$ E. F. Smiley, Ph.D. Thesis, The Catholic University of America, Washington, D.C., 1957.

${ }^{36}$ D. J. Collins and W. A. Menard, J. Heat Transfer 88, 52 (1966)

${ }^{37}$ C. S. Lee and C. F. Bonilla, Proc. Conf. Thermal Conductivity, 7th, Natl. Bur. Std., Gaithersburg, Md., 1967.

${ }^{38}$ F. A. Guevara, B. B. McInteer, and W. E. Wageman, Phys. Fluids 12, 2493 (1969).

${ }^{39} \mathrm{R}$. Dipippo and J. Kestin, Symp. Thermophys. Properties 4 th, New York, 304 (1968).

${ }_{40}$ M. Goldblatt, F. A. Guevara, and B. B. McInteer, Phys. Fluids 13, 2873 (1970).

${ }^{41} \mathrm{~J}$. Hilsenrath et al., Natl. Bur. Std. (U.S.) Circ. No. 564 (1955)

${ }^{42}$ E. A. Mason and L. Monchick, J. Chem. Phys. 36, 1622 (1962)

${ }^{43}$ I. Amdur and E. A. Mason, Phys. Fluids 1, 370 (1958).

${ }_{44}$ J. O. Hirschfelder, J. Chem. Phys. 26282 (1957).

45 J. H. Dymond and B. J. Alder, J. Chem. Phys. 51, 390 (1969).

THE JOURNAL OF CHEMICAL PHYSICS

VOLUME 57 , NUMBER 6

15 S E P T EM B E R 1972

\title{
Optimization of the Transferability of Atomic Hartree-Fock Valence Shell Orbitals*
}

\author{
William H. Adams \\ School of Chemistry, Rutgers University, New Brunswick, New Jersey† 08003 and Lehrstuhl für Theoretische Chemie der \\ Technischen Universität München, Gernany
}

(Received 8 March 1971)

\begin{abstract}
Two procedures by which atomic valence shell orbitals may be transferred between atoms have been studied numerically. The one procedure optimizes the overlap between transferred and true orbitals, and the second, the electronic energy calculated with the transferred orbitals. The two procedures give significantly different results. Both improve on the results obtained in a previous study.
\end{abstract}

\section{INTRODUCTION}

It has been shown by straightforward calculations that the valence shell, Hartree-Fock orbitals of atoms which are congeners, are in some cases quite similar. ${ }^{1}$ (We refer to this reference as I.) The degree to which these similarities might be optimized has not been studied. This paper presents the results obtained using two alternative methods of optimizing the transferability of valence shell orbitals.

The words transfer, transferable, and transferability are used frequently in this paper with special meanings. When we write that we transfer an orbital between atoms $\mathrm{A}$ and $\mathrm{B}$, we mean that we substitute some linear combination of the occupied $A$ Hartree-Fock (HF) orbitals for one orbital in the set of occupied HF orbitals of $B$, and that this $A$ orbital is orthonormalized with respect to the other orbitals in the $B$ set. How the linear combination of $A$ orbitals is chosen is discussed in Sec. II. The resultant set of orbitals is used to calculate various properties of atom $B$. If the calculated properties are identical to those found with the occupied HF orbitals of $B$, we say the $A$ orbital is exactly transferable to $B$. We find at best only approximate transferability.
The difference between the value for a property calculated with the set of orbitals including the orbital transferred from $A$ and the value calculated with the set of occupied $B$ orbitals, provides for that property a measure of the accuracy to which the $A$ orbital is transferable. The calculations in this study allow the comparison of the effectiveness of two methods of transfer. Each of these methods is optimal according to some variational criterion.

In I it was shown that if the valence shell orbitals of an atom $\mathrm{A}$ are orthogonalized to the core orbitals of an atom $B$, then normalized, the resulting functions (the transferred orbitals) are in some cases quite similar to the valence orbitals of atom B. This similarity was further investigated by evaluating various integrals for atom $B$ using the true and the transferred valence orbitals. The differences between these integrals indicated that one could not justify the substitution of transferred orbitals for the true valence shell orbitals except perhaps in the calculation of two-electron matrix elements. In the latter case it was found that the Slater integrals were in error by $10 \%$ or less for transfers from the third to the fourth period of the periodic table, in Columns III-VI. However it was argued that the 